\title{
Un virus révélateur de l'acolyte préférentiel d'un oncogène
}

\author{
Une nouvelle approche pour disséquer \\ le processus de cancérisation
}

\section{Les nouvelles de ce numéro ont été préparées par: Pascale Briand Jean-Claude Dreyfus Jean-Pierre Grünfeld Axel Kahn Marc Peschanski}

1. Van Lohuizen M, Verbeek S. Krimpenfort $\mathrm{P}$, et al. Predisposition to lymphomagenesis in pim 1 transgenic mice: cooperation with $c-m y c$ and $N-m y c$ in murine leukemia virusinduced tumors. Cell 1989; 56:673-82. 2. Panthier JJ, Condamine H. La mutagenèse insertionnelle chez la souris. médecine sciences $1988 ; 9: 568-75$.

$\mathrm{m} / \mathrm{s} n^{\circ} 6 \mathrm{vol} .5$, mai 89
De nombreux modèles d'oncogenèse ont été récemment produits par la technologie des souris transgéniques $\left(\mathrm{m} / \mathrm{s} n^{\circ} 3\right.$, vol.5, p. 166). Ils ont permis de confirmer le fait généralement admis que le processus de transformation tumorale fait le plus souvent intervenir plusieurs facteurs. En effet, l'expression' d'un transgène oncogénique dans un type cellulaire donné n'entraîne généralement la transformation que d'une fraction seulement des cellules. De plus, l'apparition de la tumeur est le plus souvent retardée par rapport au moment où le transgène commence à s'exprimer. Enfin, ces tumeurs sont en grande majorité clonales, alors que les hyperplasies qui précèdent leur apparition sont polyclonales. Ce second événement n'est certes pas rare, puisque toutes les souris transgéniques issues d'un fondateur ayant développé une tumeur vont développer un cancer, mais il est dans un sens peu fréquent puisque, comme nous l'avons dit, il ne survient que dans quelques cellules parmi toutes celles qui expriment le transgène. Les facteurs susceptibles de constituer ce deuxième événement sont multiples : stimulation hormonale, absence d'expression d'un antioncogène, surexpression d'un oncogène ou d'un facteur de croissance, et l'on conçoit bien que parmi tous ces événements potentiels, l'un d'entre eux soit particulièrement efficace pour interagir dans un contexte cellulaire donné, avec le premier événement oncogénique survenu. Ainsi, dans des lymphomes $\mathrm{T}$ résultant d'une activation de l'oncogène pim 1 par insertion du virus murin $\mathrm{MuLV}$, une surexpression de $c$ myc est souvent observée, faisant de ce gène un bon candidat pour exercer un effet fortement synergique avec pim-1. Pour confirmer cette hypothèse, M. Van Lohuizen et al. ont adopté une stratégie originale qui consiste à créer, dans un premier temps, des souris transgéniques exprimant pim 1 dans les lymphocytes [1]. Après un temps de latence important, un faible pourcentage de ces souris développent des lymphomes confirmant le caractère oncogénique de pim 1, qui avait été suspecté devant l'activation fréquente de ce gène dans les lymphomes $\mathrm{T}$ que développent des souris infectées par le virus MuLV (murine leukemia virus). Ce virus ne porte pas d'oncogène, mais il est capable d'activer les gènes cellulaires auprès desquels il s'insère (activation dite par mutagenèse insertionnelle [2]). C'est cette propriété qu'utilisent les auteurs pour identifier le facteur le plus apte à coopérer avec pim 1 dans un processus de transformation. Les souris transgéniques pim 1 sont donc infectées par le virus MuLV. En moins de sept semaines, elles développement des lymphomes $\mathrm{T}$ dans lesquels une expression élevée de l'oncogène myc est détectée et correspond dans $80 \%$ des cas à une insertion de MuLV près de $c-m y c$ et dans $20 \%$ des cas à une insertion près de $N-m y c$. Une telle fréquence d'activation montre à l'évidence que parmi les divers gènes qui ont été activés par l'intégration de l'ADN viral, l'oncogène $m y c$ est de loin le plus apte à co-agir avec pim 1 dans la leucémogenèse $T$. Cette méthodologie est très largement applicable à la recherche de gènes cellulaires ou viraux, exacerbant par synergie leur potentiel oncogénique. 